\title{
El mensaje informativo en Facebook y Twitter en las ONGD: un enfoque desde sus públicos
}

institucional.us.es/ambitos/

\section{María del Mar Soria Ibáñez}

Universidad Complutense de Madrid

msoriaibanez@gmail.com

English Version: The News of NGO in Facebook and Twitter: areceiver's point of view

\section{Resumen}

Las principales ONGD españolas utilizan, desde el año 2009, las redes sociales para emitir mensajes informativos que narran lo que sucede en el terreno. Legitiman

la cooperación y medios emergentes como Facebook y Twitter contribuyen a

fortalecer los vínculos con sus principales públicos: la propia ciudadanía. Esta investigación realiza un recorrido cuantitativo sobre la cobertura del tifón "Yolanda" que devastó Filipinas a finales de 2013. Los resultados señalan que los ingresos de

los que depende la entidad no impiden que se hagan óptimas campañas en los soportes analizados. La ciudadanía, por su parte, es el perfil que genera un mayor

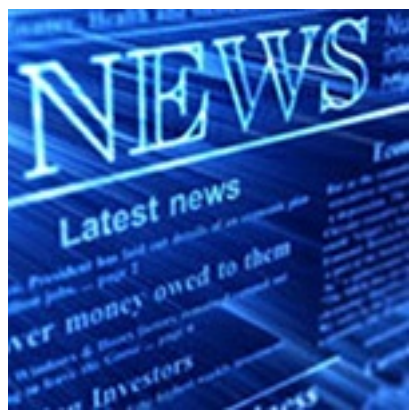
número de comentarios y retroalimenta positivamente el trabajo de las ONGD. El

análisis de contenido ha servido para determinar que la red social y el microblogging puede devolver el origen civil que sustenta la actividad de unas organizaciones que, en el caso español, necesitan más apoyo ciudadano que por parte del Estado.

\section{Palabras clave}

ONGD, redes sociales, noticias, ciudadanía.

The Spanish NGO use social networks since 2009 to emit news that describe what happens on the cooperation's ground. NGO legitimize the cooperation and emerging as Facebook and Twitter media contribute to strengthening ties with its main public: own citizens. This research takes a quantitative tour on the coverage of

the typhoon "Yolanda" which devastated Philippines at the end of 2013. The results indicate that income on which depends the entity do not prevent make optimal analyzed media campaigns. Citizenship is the profile that generates a greater number of comments and feedback positively the work of NGOs. Content analysis has been

used to determine that the social network and micro-blogging can return civil origin that supports the activity of organisations which, in the Spanish case, need more support to citizen but not from the Government.

\section{Keywords}

NGO, social networking, news, cityzenship.

\section{CONCEPTUALIZACIÓN Y ORIGEN}

Poco o casi nada sabemos sobre la importante repercusión de las redes sociales en las Organizaciones No Gubernamentales con sede en España. Aunque diversas investigaciones ya han realizado un exhaustivo repaso por la estructura comunicativa de las organizaciones del Tercer Sector (Fernández, 2004; García, 2006; González, 2006; Herranz, 2006), lo cierto es que los continuos cambios de unas organizaciones tan volátiles nos obliga a detenernos en las potencialidades que ofrecen los nuevos medios sociales para el refuerzo de los vínculos con su origen social.

En este punto cabe recordar la definición de ONG: "organizaciónque tienen su origen en la sociedad civil, que tienen trascendencia en la acción internacional y que ocupan un puesto distinto al de los gobiernos" (Marcuello, 
1996: 107).

Pero por otro lado, y de un modo más concreto, parece que el concepto de organización del Tercer Sector vinculado a la ciudadanía queda más patente a través de la actuación de las ONGD (Organizaciones no Gubernamentales para el Desarrollo). Marcuello (2007:17) pone de manifiesto lo siguiente:

"Organizaciones de carácter social, independientes y autónomas, jurídicamente fundadas y que actúan sin finalidad de lucro. Su acción se orienta hacia la Cooperación al Desarrollo y hacia la búsqueda de acuerdos de ayudas entre gobiernos con el objetivo de provocar la solidaridad y promover el desarrollo en los pueblos y sociedades del Tercer Mundo"

Granda y Lutz (1988:13), por su parte, nos hablan de que se tratan de organizaciones autónomas e independientes del ámbito de los gobiernos (aunque pueden realizar actividades conjuntas e incluso recibir de ellos parte de sus recursos), no tienen fines de lucro y sus recursos se destinan a financiar los proyectos en el ámbito de la cooperación al desarrollo.

Así, y al abrigo de las mencionadas definiciones, podemos afirmar que las organizaciones del Tercer Sector, y más concretamente aquéllas que trabajan en la cooperación al desarrollo deben tener un origen ciudadano. La sociedad es, por definición, su principal sustento, pero la realidad es bien distinta. Los datos ponen de manifiesto que la ciudadanía no es el pilar que mantiene la actividad de las ONGD en España.

Sin embargo, esa premisa tiene su explicación. Hemos de recordar que las ONGs españolas surgieron de la mano de movimientos ciudadanos al abrigo de la Iglesia Católica, pero las circunstancias políticas, sociales y económicas de cada momento las fueron transformando hasta que, en la actualidad, se han profesionalizado e institucionalizado (Gómez, 2005).

No obstante, gran parte de la bibliografía que encontramos sobre ONGs en España ponen el acento en la vinculación de su actividad a los presupuestos públicos y a proyectos que en ocasiones poco tienen que ver con su misión y valores. Por ello, determinados argumentos apuntan a que estas entidades pierden su esencia en una dura carrera competitiva hacia el hallazgo subvenciones (Gómez, 2005; Gómez, 2004; González, 2006).

Pero lo cierto es que sin fondos económicos, difícilmente se podrá materializar la ayuda humanitaria. Aunque, inicialmente, la recaudación de ese dinero podría llevarse a cabo a partir de la propia ciudadanía, ciertamente las aportaciones de particulares, en algunas ocasiones, resultan insuficientes y se deben contrarrestar con ayudas de origen público.

Los datos demuestran que la concienciación ciudadana, acompañada de una evolución del contexto histórico político, ha ido creciendo a medida que se ha ido creando un clima de libertad de expresión tras la dictadura franquista, así como la creación de entidades públicas que amparan a las ONGs y propician su profesionalización. De este modo, los datos nos dejan un claro crecimiento en el número de españoles pertenecientes a alguna organización no lucrativa, pues, si en el año 1981, hablamos de que un $30 \%$ de la población es miembro de alguna entidad no gubernamental, en el año 2002 esta cifra se incrementa en casi un 50\% (Marcuello, 2007: 87). (1)

Sin embargo, y pese a una evolución positiva entre comienzos de la década de los 80 y el año 2000, coincidiendo, según apuntan diversas teorías, con la etapa de máximo esplendor para el desarrollo de las ONGs en España, la pertenencia a una organización no lucrativa en el año 2007 aún es insuficiente. Así, Marcuello (2007: 91) revela que un 50\% de la población española masculina no es socia de ningún tipo de organización de estas características, mientras que la población femenina no miembro representa un $55 \%$. Tan sólo alrededor de un $25 \%$ de la ciudadanía, tanto femenina como masculina, pertenece a algún tipo de entidad no gubernamental. (2)

Por ello, podemos decir que las Organizaciones No Gubernamentales españolas dependen de las subvenciones públicas, pero también de la financiación privada que se hace efectiva a través de socios, donantes o empresas. Si bien es cierto que este tipo de entidades nacen desde la propia ciudadanía y se nutren de la misma, su evolución y dependencia institucional ha venido marcada por la falta de interés de la ciudadanía 
ante estas organizaciones, todo ello acompañado de unas condiciones históricas económicas poco propicias para colaborar económicamente con causas ajenas. Recordamos, en este sentido que, tras la Guerra Civil, España se enfrenta a años de recuperación económica, reestructuración de poderes políticos, reorganización y reparto de la riqueza y, en definitiva, al renacimiento de un país destrozado por el conflicto bélico. Si tenemos en cuenta esto, también resulta lógico que no sea hasta los años ochenta cuando la ciudadanía comienza a apoyar a las ONGs, coincidiendo, además, con la etapa en la que se produce el auge de su profesionalización y reconocimiento como Organizaciones No Gubernamentales.

\subsection{La planificación de la comunicación}

Podemos afirmar que el origen de los gabinetes de comunicación procedentes de organizaciones no gubernamentales se sitúa en el año 1975, cuando asistimos al fin de una dictadura y al inicio de una democracia. En este contexto, el nacimiento de diversos movimientos ciudadanos y asociaciones propició la legitimación de estos grupos como fuentes informativas, las cuales "se percataron rápidamente de la importancia que tiene la comunicación en la sociedad actual” (Ramírez, 1995: 32).

Fruto de la aparición de estos primeros departamentos dedicados a la gestión de la comunicación, las ONGs comienza a adquirir presencia en los medios de comunicación, y es a partir de 1977 "cuando se tiene constancia de las primeras informaciones en las que se menciona la labor y el papel de las organizaciones" (Gómez, 2005: 80).

Sin embargo, no sería hasta mediados de los años ochenta cuando los gabinetes de comunicación alcanzaran su máximo apogeo en España. Así, comenzaron a proliferar la creación de áreas organizacionales dedicadas en exclusiva a la gestión de la comunicación.

Dicho lo anterior, resulta lógico afirmar que no es hasta la década de los noventa cuando las ONGs españolas comienzan a ser visibles en los medios de comunicación. De hecho, hasta mediados de esta década no se aprecia una presencia notable en la prensa (Sampedro et. at., 2002: 275). Ello fue gracias a que diversas organizaciones empresariales y algunas sociales dieron en esta etapa el empujón definitivo a su comunicación, "empezando contratar personas que se ocuparan de estas tareas", como fue el caso de Médicos Sin Fronteras (Almansa, 2003: 107).

Por otro lado, esta etapa de los noventa también conlleva la profesionalización de la comunicación en las ONGs mediante la creación de áreas y personal específicos, algo que viene determinado por la consolidación, de estas organizaciones como estadidades sin ánimo de lucro en un marco legal y jurídico propio, avalado por la creación de organismos que amparaban su actividad (3). De hecho, en el año 1997, el 90 por ciento de las ONGs registradas en la CONGDE contaban con un Departamento de Comunicación y Propaganda. (Sampedro et. al. 2002: 264).

Así, fruto de esa profesionalización de los gabinetes de comunicación, algunos autores sitúan en el año 1992 el comienzo de una importante presencia en prensa de las ONGs. En este sentido, González (2006: 72) apunta a que la presencia de estas organizaciones comienza a hacerse tan latente, que se convierten en "autoridades como agentes humanitarios de desarrollo".

El año 1994 fue, sin lugar a dudas, trascendental para que las ONGs adquirieran presencia social gracias a una fuerte repercusión mediática. $Y$ es que, además de las manifestaciones sociales para pedir al Gobierno español que destinara el $0,7 \%$ del PIB, hemos de hablar de la trascendencia a nivel mundial que adquirió la crisis humanitaria como consecuencia del genocidio acaecido en Ruanda (Gómez, 2005: 84). En ambos hechos, las ONGs protagonizaron un sinfín de llamamientos a la ciudadanía y a los poderes públicos para la intervención en ambos conflictos, y por supuesto, la forma en la que se hacían escuchar era a través de los medios de comunicación.

Más tarde, en 1996, y pese a que anteriormente las ONGs habían tenido una presencia mediática medianamente positiva, asistimos a la primera manifestación de que estas organizaciones no habían aprendido aún a ser fuentes de información. Prueba de ello es que en este año se publicaron los primeros artículos y reportajes amplios en los que "se criticaba la labor de las ONGs españolas en sus proyectos de cooperación 
con el Tercer Mundo y en su labor humanitaria, haciendo referencia a algunos déficit anteriores" (Gómez, 2005: 85).

Otro de los errores en los que cayeron las ONGs españolas fue en el de facilitar información a todos los periodistas que la solicitaban. De este modo, se proveían imágenes dramáticas y virulentas, con el objetivo de que los periodistas no dejaran de interesarse por ellas. Esta es una tendencia visible sobre todo a partir del año 2000. (González Luis, 2006: 73).

Podemos afirmar que la evolución de los departamentos de comunicación en organizaciones no gubernamentales viene determinada por el hecho de tratarse de organizaciones que adquirieron su mayor auge cuando las instituciones públicas comenzaron a crear organismos y políticas dedicados a la cooperación internacional y la ayuda al desarrollo. Ello ocurrió en los años ochenta, y por ello es durante esta década cuando se aprecia el mayor volumen de ONGs. De hecho, autores como Serrano (2001: 141), amparan la teoría de que el crecimiento y consolidación de este tipo de entidades en los años ochenta vino determinado por diversos acontecimientos políticos, tales como la entrada de España en la Unión Europea. Además, la creación, en el año 1982, de la CONGDE, ayudó a establecer un marco de oficialidad para dar cobertura a esas nuevas instituciones solidarias y humanitarias.

Sin embargo, y pese a que hablamos de que los departamentos de comunicación de las ONGs españolas no comienzan a ser una realidad hasta mediados de la década de los noventa, en el año 2004 se aprecia un crecimiento importante en el número de departamentos de comunicación, pues se da un incremento del $50 \%$ con respecto al año 1996, en el que sólo el 3\% de las ONGs poseían un área dedicada a la comunicación. (García Orosa, 2006: 57).

Por otro lado, podemos afirmar que la cuestión de la creación de un departamento de comunicación viene determinada por el presupuesto que tenga la organización. De hecho, una de las bases de las que parte esta investigación es que, cuanto más presupuesto tenga una ONG, más ricas serán las estrategias desarrolladas por el departamento de comunicación. En este sentido, Sampedro et. al (2002: 264), corroboran esta pesquisa, pues en un estudio en el que analizaron 88 organizaciones no gubernamentales españolas en el año 1997, concluyeron que "existe una correlación positiva entre las ONG con mayor volumen de ingresos y fuentes de financiación y la presencia de Departamentos de Comunicación y propaganda” (4).

\subsection{La comunicación en la Web 2.0}

En lo que respecta a las principales características de la relación que se establece entre las ONGs e Internet, podemos remitirnos a los estudios de Kent, Taylor y White (2002). Estos autores defienden que la creación de una web optimiza las relaciones de una entidad no gubernamental con sus públicos, especialmente con los voluntarios. Ello se debe, fundamentalmente, a que estos públicos internos, no remunerados, han de realizar el mismo trabajo que el personal retribuido, y la creación de un espacio propio para ellos es una forma de motivarlo e incentivarlo..

Sin embargo, aún queda mucho camino por recorrer. Ingenhoff y Koelling (2007) llevaron a cabo un análisis de las páginas webs de diferentes ONGs suizas, y descubrieron, entre otros aspectos, que hay una gran ausencia de elementos que permitan el feedback con el usuario. Por ello, la inclusión de espacios que permitan a la ciudadanía opinar y participar a través de la web es fundamental para que el público confíe en los proyectos de una ONG. Sin embargo, tanto a nivel internacional como en el propio caso español, sigue habiendo una gran desconfianza a otorgarle la palabra al usuario.

Además, del estudio citado anteriormente, otros muchos, como los desarrollados por Naudé et al (2003), o Greenberg y MacAulay (2009), han visto también que la influencia de Internet en la gestión de la comunicación y de las relaciones públicas en las ONGs no sólo es un fenómeno en alza sino también un acontecimiento que cuenta con características particulares que se han de analizar, para poder establecer conclusiones que sirvan para la mejora y optimización de las estrategias desarrolladlas por las entidades no gubernamentales a través de la Red. Así, tanto las dos investigaciones citadas anteriormente, como otras muchas que se están gestando en la actualidad, hacen hincapié en que las ONGs que hacen uso de las Nuevas Tecnologías, y más concretamente de la Web 2.0 y sus herramientas, como formas para fortalecer sus relaciones con sus públicos, 
han de reforzar aún más estas técnicas digitaleshaciendo hincapié en aspectos claves tales como la actualización de contenidos, la inclusión de herramientas bidireccionales (blogs, RSS, e-gestión) y, en definitiva, han de otorgar un espacio propio al usuario para que éste interactúe con la organización de forma libre y democrática.

En la línea anterior, debemos señalar las aportaciones que nos dejan Kang y Norton (2004: 279-284), quiénes realizaron un repaso por las herramientas usadas por las ONGs para relacionarse con sus públicos, y descubrieron una falta latente de estrategias.

"Most organizations sampled used simple designs in their Web sites by providing minimal animation (94\%) (...). However, the organizations are not utilizing the benefits of the Web to attract more visitors. Current NPOs need to develop better quality designs appealing to visitors. Although the sites look simple in design the authors envisage that the design of many sites actually proved to be of low quality"

No obstante, y aunque, como dejamos constancia, determinados estudios internacionales ya han puesto de manifiesto la relación inexorable, e incluso necesaria, entre organizaciones del Tercer Sector y Web 2.0, no conocemos realmente la traslación de esta idea al caso español. Por ello, y porque Internet avanza poderosamente, consideramos imprescindible detenernos en desgranar todas las preguntas que rodean a la unión de las ONGD con sus públicos mediante las plataformas que otorgan la palabra a la sociedad.

\section{OBJETIVOS}

Como se ha expuesto en el marco teórico, la escasez de estudios dedicados al posicionamiento de las ONGD en redes sociales como herramienta para potenciar su imagen entre sus públicos reales y potenciales nos ha llevado a poner de manifiesto las características de este fenómeno. Se considera necesario reflejar el estado actual de la intervención de las organizaciones en la Web 2.0 para conocer las relaciones que se establecen entre las entidades y el mapa de públicos. Por lo tanto, nos planteamos los siguientes objetivos:

- Analizar si las ONGD que tienen un mayor potencial económico son también las que despliegan un mayor volumen de contenidos en Facebook y Twitter, con el fin de poner de manifiesto si la gratuidad de los soportes potencia el uso por parte de entidades con menos fondos.

- Profundizar en el tono de los contenidos publicados por las organizaciones para poder conocer si usan los medios sociales para fines publicitarios o informativos.

- Determinar el mapa de públicos de cada entidad para profundizar en el grado de vinculación entre éstos y la ONGD, y conocer de este modo las alianzas establecidas entre las entidades no lucrativas de mayor calado en España y el tipo de público al que se acoge para optimizar su imagen de marca.

- Conocer el volumen y el tono de los mensajes que adquieren los comentarios de la ciudadanía en ambos soportes objeto de estudio, con el fin de determinar la inclinación de ésta sobre las actividades de cooperación de las ONGD.

\section{METODOLOGÍA}

Para alcanzar los objetivos planteados hemos partido del análisis de contenido del posicionamiento de las ONGD objeto de estudio en los espacios virtuales 2.0 de mayor impacto social: el microblogging Twitter (5) y la red social generalista Facebook (6).

El análisis en Twitter ha servido para determinar el uso diario del microblogging por parte de la ONGD, así como el grado de interacción de la misma a través de la cuantificación de noticias diarias. Igualmente, nos ha ayudado a conocer el perfil de sus seguidores (públicos externos e internos) y el tono que adquieren las intervenciones de los mismos. De igual modo, este análisis ha sido de utilidad para conocer la intencionalidad y modos de participación de los diversos públicos que intervienen en las cuentas de Twitter de las entidades analizadas. Hemos podido determinar también la sensibilización de la ciudadanía y la cooperación que se genera a través de los mensajes de 140 caracteres. Los mencionados criterios de estudio han facilitado el establecimiento de conclusiones en torno a la cuantificación media de mensajes lanzados por las entidades, su número de 
seguidores, los tipos de públicos que interaccionan con las principales ONGD españolas y el tono de los mensajes que emiten los usuarios respecto a la actividad de éstas.

En el caso de Facebook, los criterios que han llevado al planteamiento de resultados han seguido la misma línea que el microblogging. Sin embargo, recordemos, por las diferencias importantes que existen entre la configuración de un soporte y otro, en esta última red social también se ha abordado el uso del material multimedia para completar los contenidos vertidos por las ONGD.

\subsection{Muestra}

El estudio ha partido de la selección de las 10 ONGD que cuentan con un mayor volumen de ingresos anual. La referencia para esta elección ha sido el Informe de la Coordinadora de ONG para el Desarrollo-España sobre el sector de las ONGD (2011) (7) (8).

La motivación que ha llevado a seleccionar las organizaciones se ha formulado a partir de la premisa de investigaciones previas que atestiguan que, cuanto más presupuesto tenga una ONG para desarrollar su actividad anualmente, más inversión en tiempo y en capital (9) destinará a la gestión de la comunicación. Así, los estudios de Sampedro et al (2002:283) y el trabajo de Fernández Torres (2004:896) nos llevan a afirmar que las 10 primeras ONGD que ocupan las primeras posiciones en el ranking presupuestario tendrán también un mayor y eficaz posicionamiento en Twitter y en Facebook.

Por lo tanto, el estudio ha partido de las 10 ONGD que han ejecutado un volumen de ingresos (privados y públicos) que oscila entre los 79.758 .000 euros y los 21.854 .032 euros.

\begin{tabular}{|c|c|c|c|c|c|c|}
\hline \multicolumn{7}{|c|}{ TABLA 1: ONGD E INGRESOS EJECUTADOS } \\
\hline NOMBRE DE LA ONGD & $\begin{array}{c}\text { INGRESOS } \\
\text { EJECUTADOS } \\
\text { PRIVADOS 2010 } \\
\text { (Euros) }\end{array}$ & $\begin{array}{c}\text { INGRESOS } \\
\text { EJECUTADOS } \\
\text { PÚBLICOS 2010 } \\
\text { (Euros) }\end{array}$ & $\begin{array}{c}\text { OTROS } \\
\text { INGRESOS } \\
2010 \text { (Euros) }\end{array}$ & $\begin{array}{c}\text { TOTAL } \\
\text { INGRESOS } \\
\text { EJECUTADOS } \\
2010 \text { (Euros) }\end{array}$ \\
\hline INTERMON OXFAM & 51.475 .348 & $65 \%$ & 27.276 .041 & $34 \%$ & 1.006 .611 & 79.758 .000 \\
\hline UNICEF ESPANA & 53.792 .173 & $90 \%$ & 5.906 .149 & $10 \%$ & 95.649 & 59.793 .791 \\
\hline $\begin{array}{c}\text { CRUZ ROJA } \\
\text { ESPANOLLA }\end{array}$ & 25.994 .640 & $46 \%$ & 30.440 .641 & $54 \%$ & 179.347 & 56.614 .628 \\
\hline AYUDA EN ACCION & 36.440 .437 & $65 \%$ & 16.559 .029 & $29 \%$ & 3.165 .523 & 56.163 .989 \\
\hline MANOS UNIDAS & 41.384 .744 & $78 \%$ & 10.304 .954 & $19 \%$ & 1.303 .874 & 52.993 .572 \\
\hline $\begin{array}{c}\text { ACCION CONTRA EL } \\
\text { HAMBRE }\end{array}$ & 6.182 .026 & $14 \%$ & 38.880 .037 & $86 \%$ & & 45.062 .063 \\
\hline CARITAS ESPANOLA & 15.545 .484 & $54 \%$ & 7.666 .739 & $26 \%$ & 5.723 .525 & 28.935 .748 \\
\hline MEDICOS DEL & 7.592 .869 & $33 \%$ & 15.598 .000 & $67 \%$ & & 23.198 .869 \\
\hline MUNDO & & & & & & 22.096 .133 \\
\hline MEDICUS MUNDI & 2.825 .871 & $13 \%$ & 19.270 .262 & $87 \%$ & & 21.854 .032 \\
\hline $\begin{array}{c}\text { FUNDACION } \\
\text { ENTRECULTURAS }\end{array}$ & 12.310 .758 & $56 \%$ & 9.543 .274 & $44 \%$ & & \\
\hline
\end{tabular}

Fuente: CONGDE (2011)

\subsection{Período de análisis}

El estudio se ha realizado durante el mes de noviembre de 2012. La razón que nos ha llevado a seleccionar este espacio temporal es porque se trata del penúltimo mes del año, y un período muy propicio para publicar datos sobre la actividad anual de las organizaciones. Pese a que hubiera sido también factible centrarnos, bajo el mencionado criterio, en el último trimestre del año 2013 (octubre, noviembre y diciembre), partimos de la base de que los resultados aquí expuesto suponen ya una representatividad de ese período, teniendo en cuenta que diciembre es el mes que resume los 11 anteriores (10).

Pero además, también se ha tratado de un mes especialmente noticiable para las ONGD analizadas, pues todas ellas, de una u otra manera, han estado implicadas en la cooperación con el desastre de Filipinas. Ello, 
sin duda alguna, ha aumentado la actividad de las entidades en los soportes 2.0 analizados, y es un factor clave para resaltar la importancia del período de análisis seleccionado como representativo del modelo de comunicación estratégico desarrollado en la Web 2.0, con especial incidencia en Twitter y en Facebook.

\section{Principales resultados}

A modo de contextualización, debemos partir de la base de que la fecha de inicio de actividad en las redes sociales se inicia para determinadas organizaciones en el año 2009. Sin embargo, tal y como se puede apreciar en los resultados, no necesariamente las ONGD que comienzan antes sus estrategias en las comunidades virtuales son las que tienen en la actualidad los picos de actividad más notorios.

Resalta especialmente el caso de Cáritas o Entreculturas, dos entidades que se posicionaron a partir de 2009 y que en términos de seguidores representan los volúmenes inferiores (11).

\begin{tabular}{|c|c|c|}
\hline ONGD & FACEBOOK & TWITTER \\
\hline Intermón. Qxfam & 2010 & 2010 \\
\hline \multicolumn{3}{|l|}{ Unicef } \\
\hline Cruz Roja & 2009 & 2010 \\
\hline \multicolumn{3}{|l|}{ Ayuda en Acción } \\
\hline \multicolumn{3}{|l|}{ Manos Unidas } \\
\hline Acción contra el Hambre & 2009 & 2010 \\
\hline Cáritas Española & 2009 & 2010 \\
\hline Médicos del Mundo & 2011 & 2011 \\
\hline \multicolumn{3}{|l|}{ Medicusmundi } \\
\hline Fundación Eotreculturas & 2009 & 2009 \\
\hline
\end{tabular}

Fuente: Elaboración propia

\subsection{Twitter}

El estudio de las 10 ONGD con el mayor volumen de ingresos ejecutados nos ha llevado a cuantificar un total de 1.527 noticias vertidas por las entidades objeto de estudio. Pero además, todas las cuentas arrojan una cifra absoluta de 298.213 seguidores que, intervengan o no en el perfil de las organizaciones, son testigos de las noticias emitidas por éstas y de las interacciones de los usuarios que sí participan en el soporte de comunicación 2.0.

La ONGD que arroja un mayor número de noticias es Manos Unidas, hasta llegar a la totalidad de 560 durante el mes de noviembre. Ello también provoca que sea la organización que genere un mayor volumen de informaciones de media diaria, de tal manera que encontramos una ratio de 10 noticias.

En este punto también se aprecia una conclusión importante, pues percibimos que en la comunicación online no tienen aplicabilidad las teoría vertidas por investigaciones previas (Sampedro et al, 2002; Fernández Torres, 2004 y Soria, 2011) que ponen de manifiesto que, cuanto más ingresos y presupuesto tenga una entidad no lucrativa, más inversión realizará en comunicación. Ello nos resulta coherente. Es decir, en este criterio tiene una gran lógica que una organización que no es la más poderosa económicamente como Manos Unidas, sea la que se sitúe a la cabeza en la emisión de noticias diarias. Ello viene determinado por el razonamiento de que, al contrario que en el modelo de comunicación offline, estudiado ampliamente en las mencionadas investigaciones, con la Web 2.0 se abarata la gestión de la comunicación y por ello organizaciones que tradicionalmente han invertido menos en imagen (Soria, 2011) ahora optimicen las relaciones con los públicos a través de los medios 2.0 aunque dispongan un presupuesto inferior. 


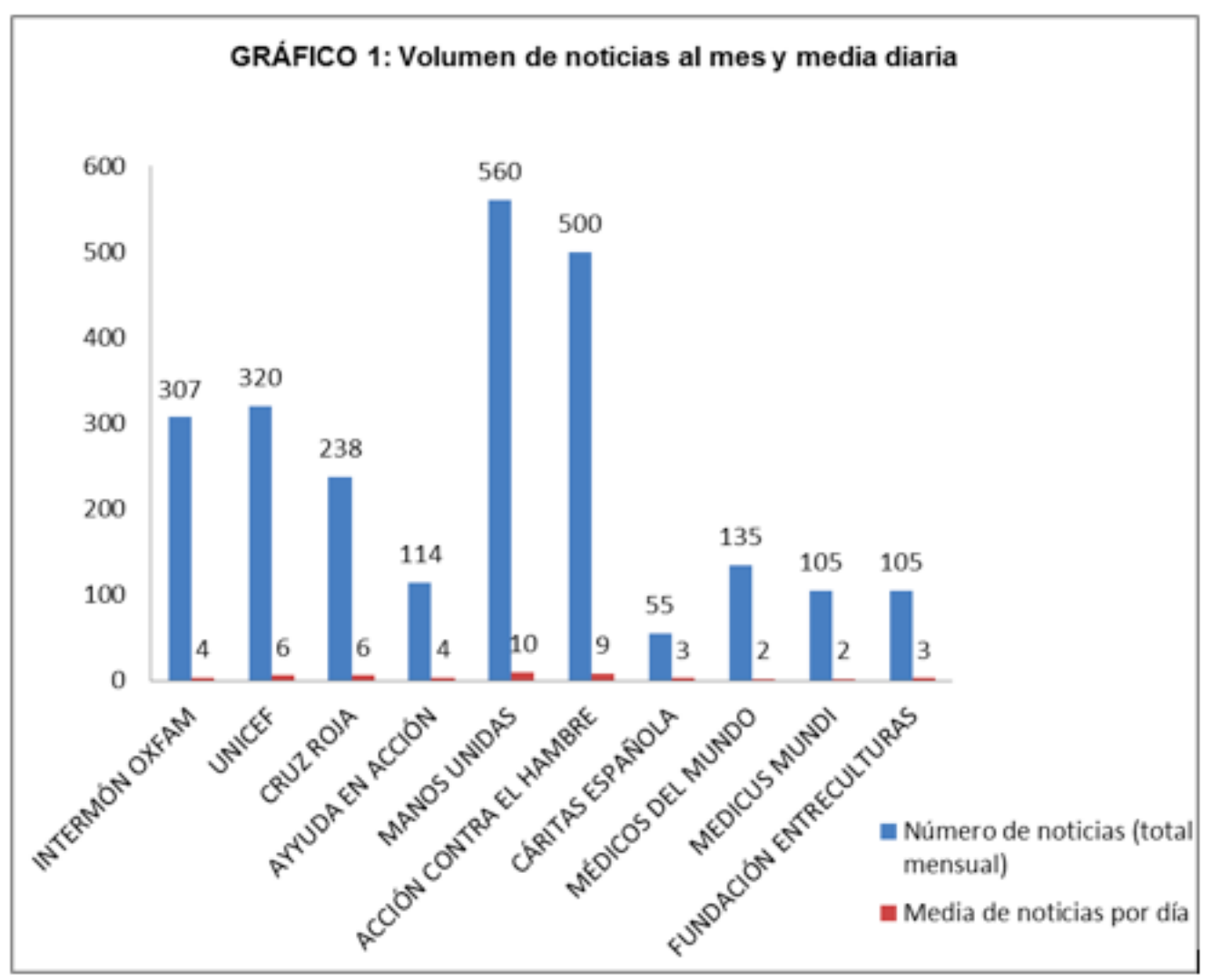

Fuente: elaboración propia

Por otro lado, el análisis del número de seguidores de cada ONGD pone de manifiesto que el criterio del volumen de noticias no está vinculado a un mayor o menor número de usuarios fieles a la marca en Twitter. Así, por ejemplo, y en el caso de UNICEF, que presenta un total de 320 noticias durante el período analizado, es la entidad que presenta un mayor número de seguidores con una gran ventaja sobre las demás (157.667 seguidores en términos absolutos). Pensamos que ello viene determinado por tratarse de una organización internacionalmente conocida. Entendemos que es una de las más populares entre los usuarios, y ello genera que, independientemente de los contenidos que genere en el microblogging, su actividad será seguida por más usuarios. No ocurre lo mismo en el caso de otras ONGD más prolíferas en la difusión de mensajes, como puede ser Manos Unidas. Pese a tratarse de la ONGD con un mayor volumen de información, es la organización que presenta un menor número de seguidores (5.046). Es reseñable también el caso de Cáritas, puesto que aunque solamente presenta 55 noticias, tiene un número de seguidores importante (40.136), y se sitúa como la tercera ONGD con más seguidores, solamente por detrás de UNICEF (157.667) y Cruz Roja (45. 631). 


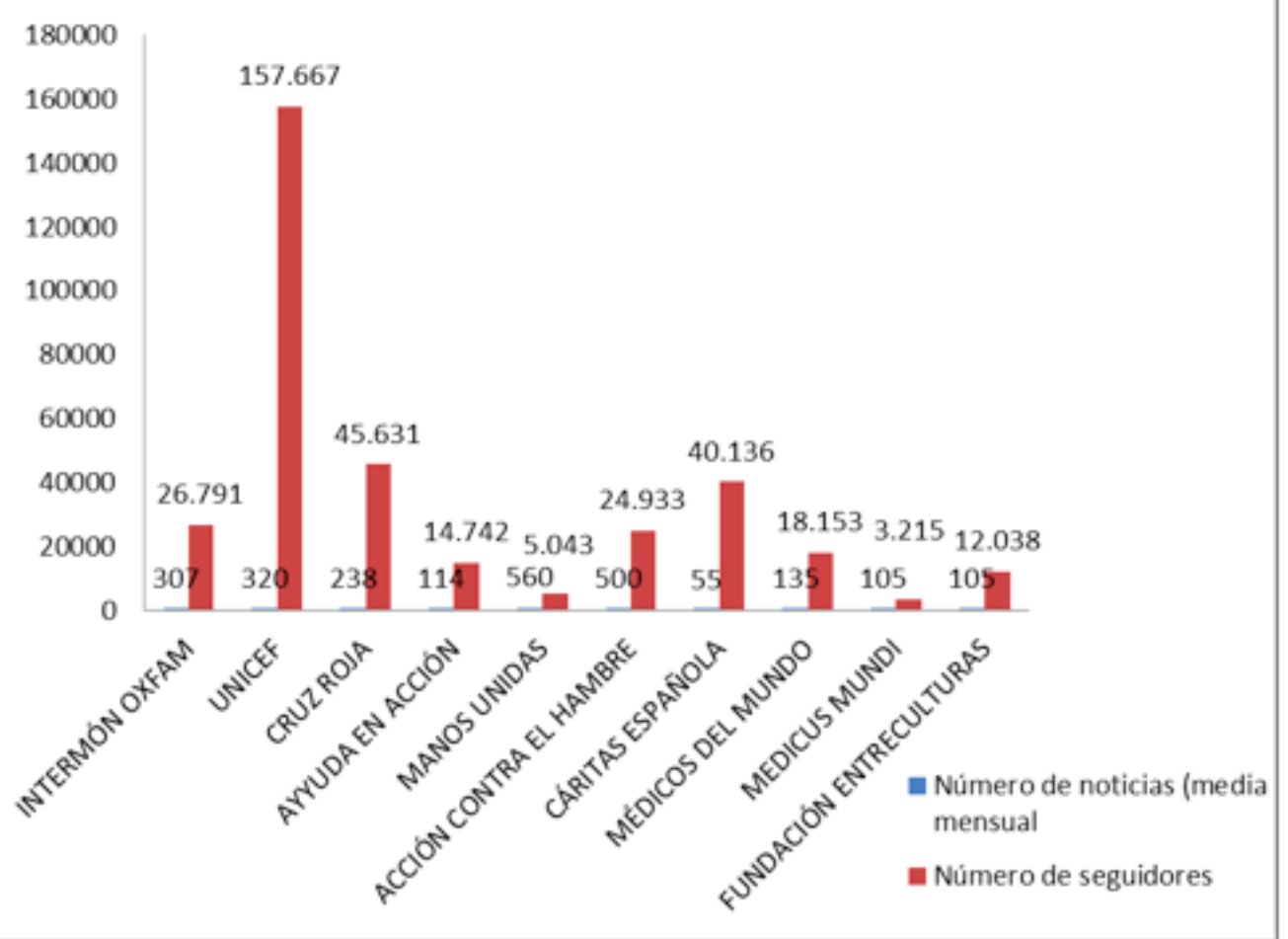

Fuente: elaboración propia

El mapa de públicos es muy diverso dependiendo de la ONGD analizada. Sin embargo, todas las organizaciones que han formado parte del estudio contienen de forma mayoritaria comentarios procedentes de ciudadanos de a pie. Acción Contra el Hambre es la entidad que recibe más apoyo social a través de mensajes orientados a visibilizar la campaña de la organización para cooperar en el desastre de Filipinas. De hecho, 105 mujeres y hombres de un total de 135 usuarios acogidos a distintos grupos (12) refuerzan su campaña online. Un tema que se repite con frecuencia entre el resto de usuarios que aportan comentarios a las cuentas de Twitter. Destacan también los casos de Médicos del Mundo (52) y UNICEF (50), que, aunque presentan una representatividad ciudadana menor, también cuentan con el impulso social necesario para que su imagen sea aún más pública en la Red. En el caso de Cáritas, no encontramos ni una sola mención de la ciudadanía. Entendemos que la ONGD tiene vetado el uso de su cuenta a personas externas, puesto que solamente se encuentran mensajes de la propia organización y de otras afines o de sus delegaciones autonómicas.

Destacan también los contenidos vertidos por las ONGD externas que apoyan las campañas de cada una de las entidades analizadas. En este sentido es reseñable el caso de Medicus Mundi, que cuenta con la intervención de 14 ONGD con las que no tiene vínculos de cooperación y/o campañas compartidas. Llama la atención también en este punto que solamente 5 ONGD afines y/o con la que comparte campañas de sensibilización sean las que vierten mensajes que refuercen la acción 2.0 de la señalada organización. Una tendencia que se repite, como se puede apreciar en el gráfico, en la mayoría de las entidades, donde prevalece el apoyo online de otras organizaciones externas a su actividad. Ello viene determinado por la coyuntura generada por la tragedia de Filipinas, que genera de forma extraordinaria una cooperación inter ONGD necesaria y eficaz.

En cuanto a la presencia de los medios de comunicación, los periodistas tienen un protagonismo medio. Las ONGD que recibe un mayor número de mensajes del colectivo son Intermón Oxfam y Manos Unidas. Recordemos que esta última organización es la que emite un mayor número de noticias durante el período analizado (560) y la visibilidad que se autogenera en Twitter puede reportarle un mayor conocimiento por parte de los profesionales de la información. Ello le ayuda, sin duda alguna, a que su presencia en los medios sea más evidente. En el caso de Intermón Oxfam, su carácter internacional contribuye a la mediatización de sus mensajes informativos en el microblogging. 
http://dx.doi.org/10.12795/Ambitos.2014.27.02

\begin{tabular}{|c|c|c|c|c|c|c|c|c|}
\hline & Ciudadanfa & Periodistas & \begin{tabular}{l|} 
ONG \\
externa
\end{tabular} & \begin{tabular}{|l|} 
ONG \\
vinculada
\end{tabular} & $\begin{array}{l}\text { Personajes } \\
\text { populares }\end{array}$ & $\begin{array}{l}\text { Públicos } \\
\text { internos }\end{array}$ & Empresas & $\begin{array}{l}\text { Administración } \\
\text { pública }\end{array}$ \\
\hline $\begin{array}{l}\text { Intercosina } \\
\text { oxfan. }\end{array}$ & 49 & 7 & 4 & & 1 & & & \\
\hline UNICEF & 50 & 9 & 3 & & 8 & & 3 & \\
\hline Cruz Roja & 4 & 1 & 3 & 7 & & 2 & & \\
\hline $\begin{array}{l}\text { Ayuda en } \\
\text { Acción }\end{array}$ & 18 & 2 & 2 & 2 & 2 & & 3 & \\
\hline Manos Unidas & 49 & 7 & 4 & & 1 & & & \\
\hline $\begin{array}{l}\text { Acción contra } \\
\text { el Hambre }\end{array}$ & 105 & 11 & 9 & & 2 & 2 & 3 & 1 \\
\hline $\begin{array}{l}\text { Cáritas } \\
\text { Española }\end{array}$ & & & 1 & 19 & & & & \\
\hline $\begin{array}{l}\text { Médicos del } \\
\text { Mundo }\end{array}$ & 52 & 4 & 2 & 4 & 1 & 2 & & 1 \\
\hline Medicusmundi & 13 & 4 & 14 & 5 & & & & \\
\hline $\begin{array}{l}\text { Fundación } \\
\text { Entresulturas }\end{array}$ & 25 & & & 8 & & & & \\
\hline
\end{tabular}

Fuente: elaboración propia

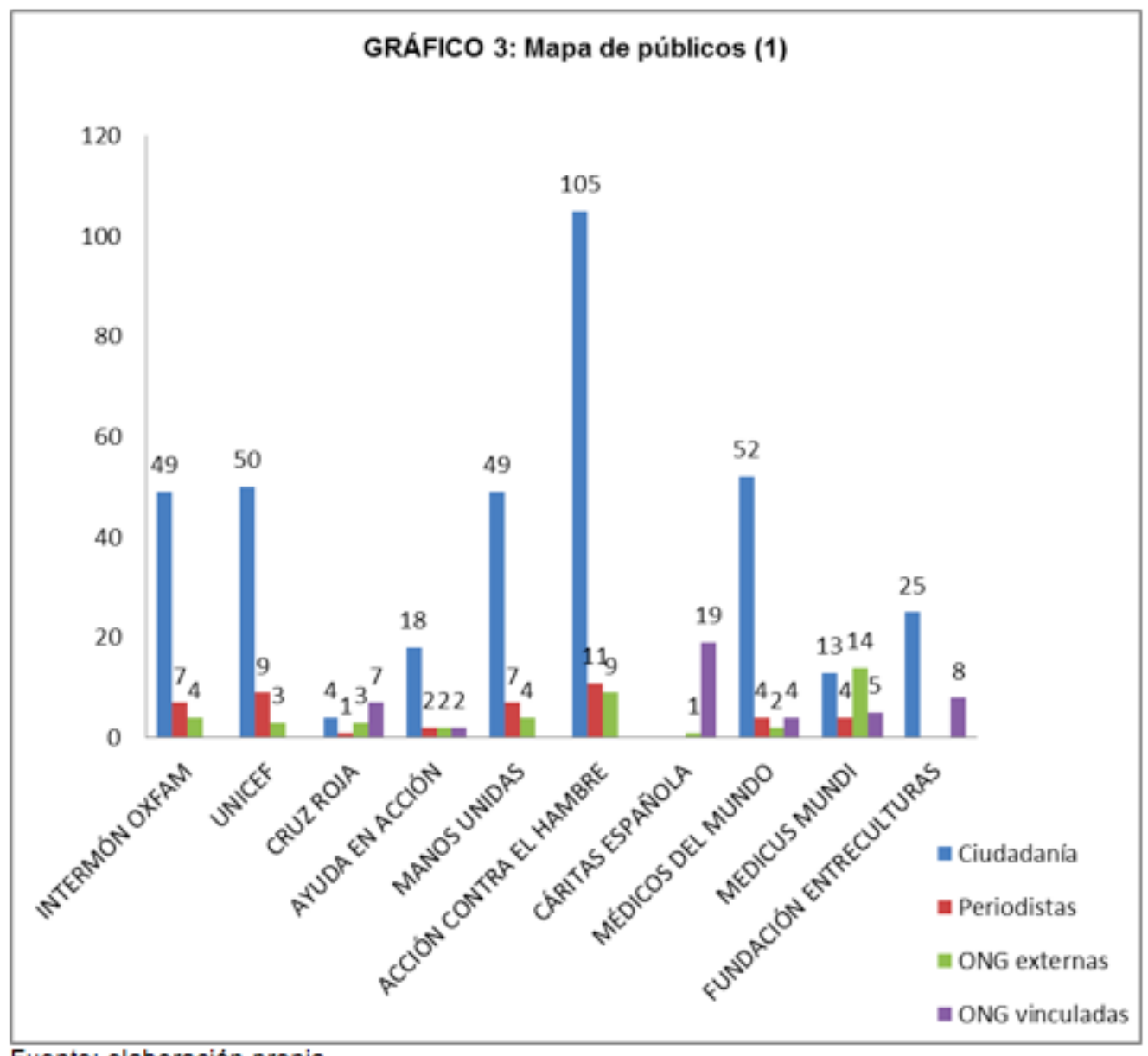

Fuente: elaboración propia 


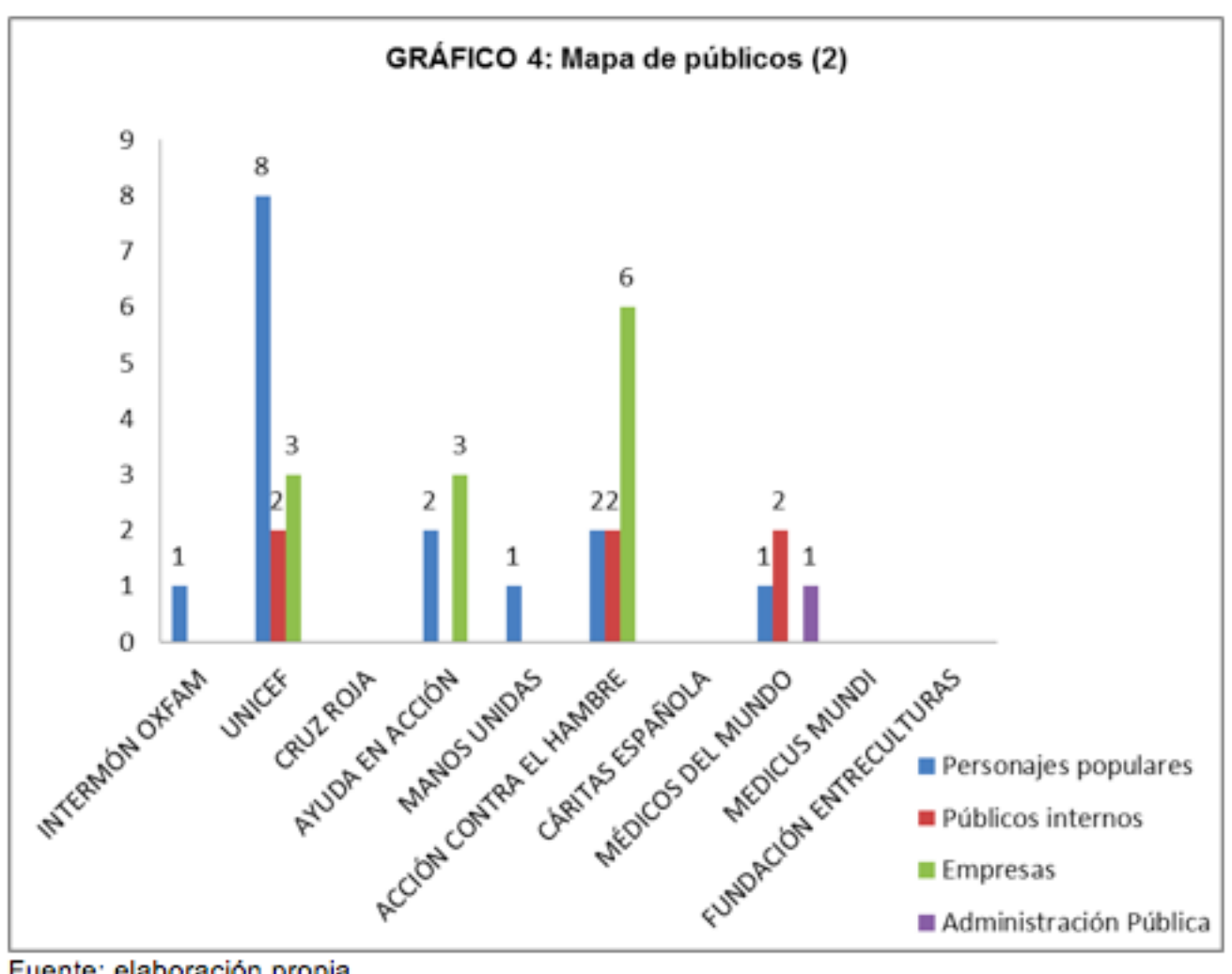

Fuente: elaboración propia

Los personajes populares son más numerosos en UNICEF, una ONGD que mantiene muy presente la mencionada estrategia de notoriedad en sus campañas offline, y que repite en Twitter con el objetivo de tener una mayor visibilidad.

Destaca también el apoyo empresarial que generan las empresas a algunas organizaciones, especialmente en el caso de Acción Contra el Hambre, con una fuerte presencia de la entidad financiera BBVA.

El dato negativo lo encontramos en el protagonismo que adquieren los públicos internos de las organizaciones analizadas. En pocas ocasiones encontramos los testimonios, llamadas a cooperar o noticias emitidas por parte de los voluntarios o trabajadores. Y es que solamente UNICEF, Acción Contra el Hambre y Médicos del Mundo cuentan con el apoyo de su personal para difundir las campañas de las organizaciones.

Volviendo al papel de la ciudadanía, hemos visto claramente que las intervenciones de los grupos sociales han servido para apoyar las campañas de las ONGD, si bien es cierto que, tal y como se ha comprobado, en algunas entidades la presencia ciudadana es mayor que en otras (13).

En cuanto al contenido de la información que publican las organizaciones seleccionadas, comprobamos que en términos generales no es habitual la llamada directa a la cooperación ciudadana, entendiendo esta acción como reclamo publicitario. Twitter se convierte en una herramienta para sensibilizar a la ciudadanía a través de las historias humanas que forman parte de los proyectos de cooperación de las ONGD. Del mismo modo, también con recurrentes los comentarios en los que se ofrece un enlace a la página web de la organización para conocer los testimonios de los voluntarios y cooperantes que se encuentran en el terreno.

Por lo tanto, la información prevalece por encima de la publicidad. Y es que, insistimos, lo más habitual es utilizar un lenguaje positivo vehiculado a contar historias de éxito o centrado el discurso en el trabajo de la entidad. En la mayor parte de estos casos se usa un enlace externo para informar de forma ampliada a la ciudadanía, generalmente a través de la propia página web.

Vemos en el gráfico, por lo tanto, que en todas las ONGD analizadas se priorizan los discursos anteriores. Manos Unidas se vuelve a posicionar como la entidad que lanza un mayor número de mensajes de carácter informativo, algo que viene determinado por tratarse de la ONGD que lanza más mensajes durante el mes de noviembre. Así, el $97,8 \%$ de sus mensajes (548) se convierten en noticia. Y es que no solamente se trata de la cobertura informativa del desastre de Filipinas (a través de los testimonios de sus voluntarios o de las historias 
de vida), sino que difunde de forma eficaz las informaciones que tienen que ver con sus campañas de sensibilización ciudadana.

El resto de las organizaciones siguen también esta tónica, aunque el hecho de que emitan un menor volumen de comentarios diarios merma su función informativa a través de Twitter.

Insistimos, no obstante, de que prevalece la tónica general de omitir una llamada a la cooperación ciudadana a través de mensajes del tipo "colabora", "dona" o "te necesitamos".

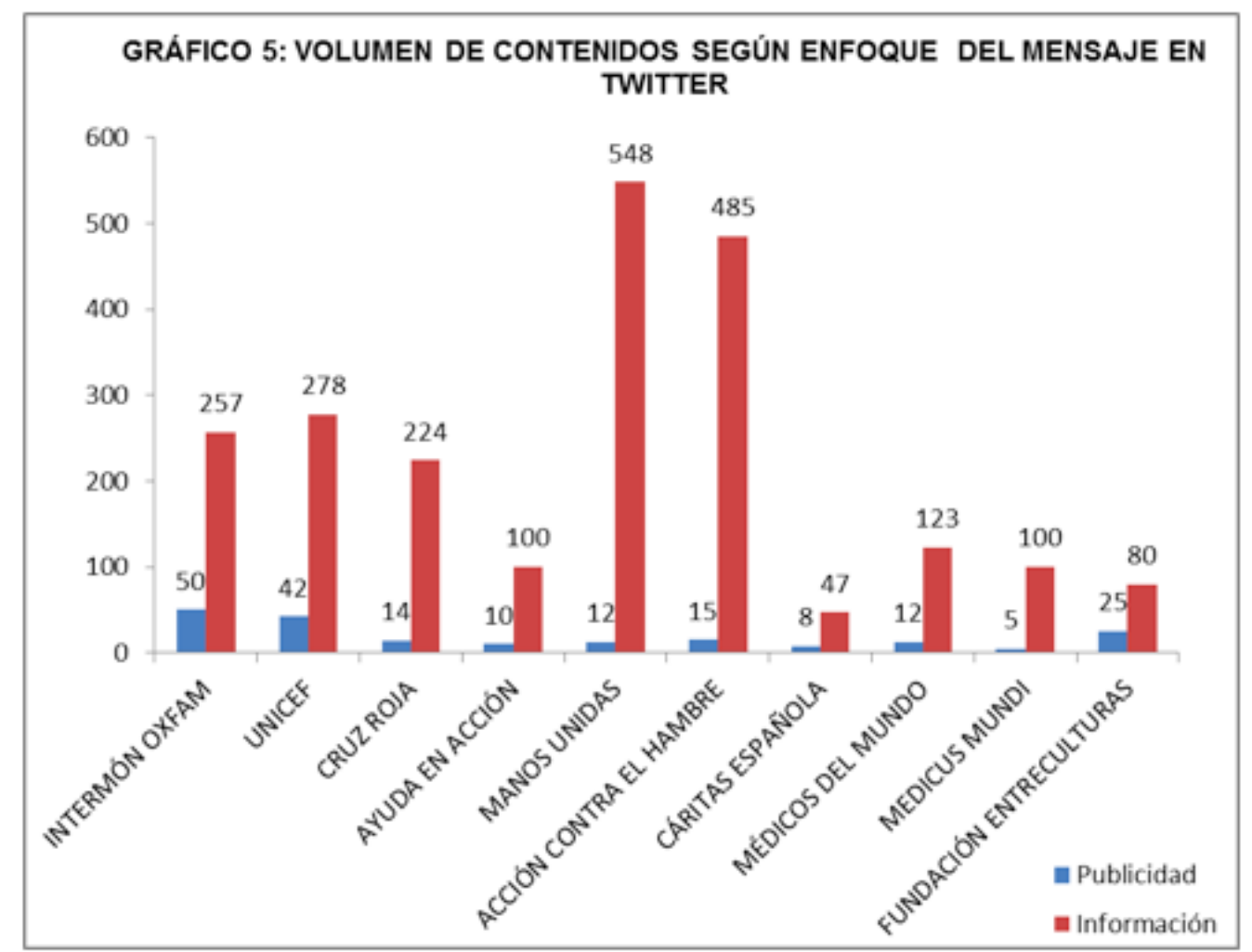

Fuente: elaboración propia

\subsection{Facebook}

Esta red social de corte generalista permite detectar fácilmente si la organización objeto de estudio otorga libertad o no a la ciudadanía para generar contenidos con total libertad. Ello nos ha permitido comprobar que todas las ONGD analizadas, a excepción de Cáritas y Manos Unidas, ofrecen a sus públicos la posibilidad de interaccionar con la entidad a través de sus mensajes.

La mayoría de las ONGD tiene una mayor popularidad en Facebook que en Twitter, pese a que el volumen de intervenciones en la red social que describimos es menor. Así, hay una notoria diferencia, por ejemplo, en el caso de Manos Unidas, que consigue 97.451 seguidores en Facebook frente a los 5.043 que mantiene Twitter. Una tendencia que no se manifiesta en Unicef, la única organización que mantiene, con una holgada diferencia, la supremacía de seguidores en Twitter frente a Facebook (157.667 frente a 86.824 respectivamente). 


\section{GRÁFICO 6: VOLUMEN DE SEGUIDORES EN FACEBOOK Y TWITTER}

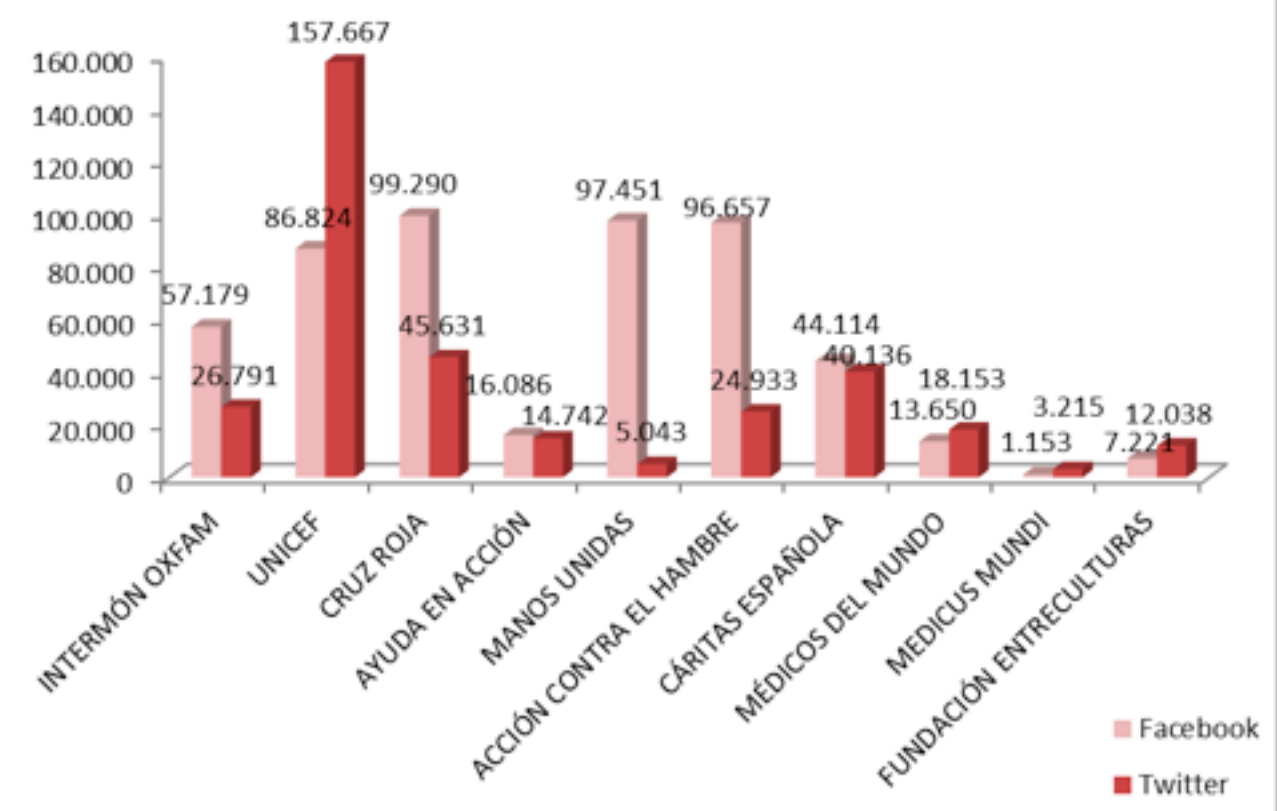

Fuente: elaboración propia

Tal y como se muestra en el Gráfico 7, todas las ONGD tienen una mayor actividad en Twitter. Entendemos que el mensaje de 140 caracteres es más claro y conciso y su instantaneidad permite cargar con mayor rapidez y fluidez contenidos noticiosos de la organización. Es por ello que la mayoría de mensajes susceptibles de convertirse en noticia para los medios de comunicación se encuentran en el microblogging. Sin embargo, y pese a que el volcado de contenidos informativos es mucho más fluido en Twitter, debemos recordar que el mayor número de seguidores por cada entidad estudiada se registra en Facebook. Ello puede deberse a que el perfil del usuario habitual de Twitter está sesgado. De hecho, y según la Asociación Española de Economía Digital, el $51,9 \%$ de los usuarios están en contacto permanente con la información mediática y posee un máster. Pero además, se ha de tener en cuenta que el número de usuarios de Facebook en España alcanza los 15 millones, mientras que en Twitter la cifra desciende hasta los 4,5 millones (14). Ello también condiciona la diferencia cuantitativa entre una red social y otra, aunque no condiciona, tal y como se ha apuntado, el grado de interacción online. 


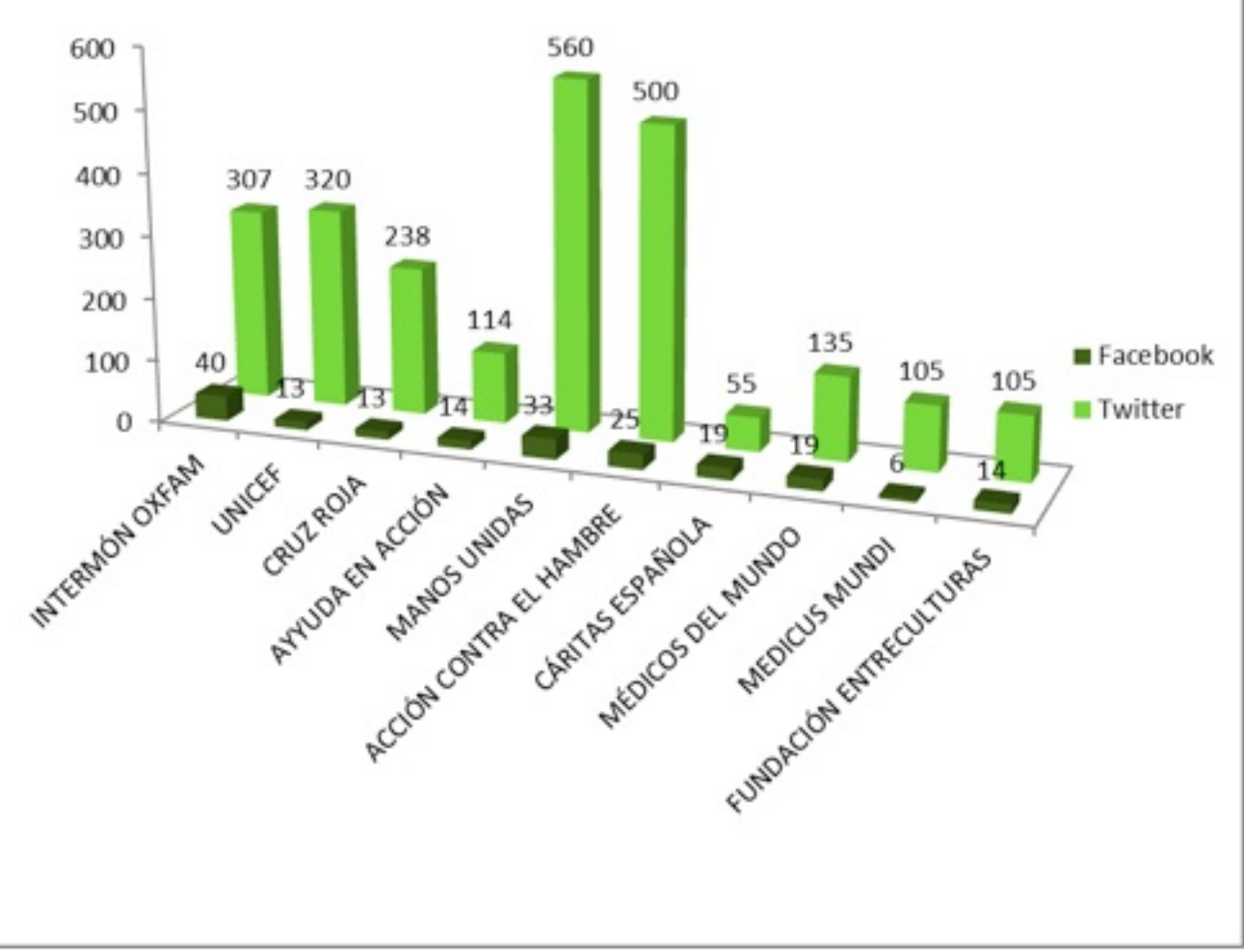

Fuente: elaboración propia

En lo que se refiere al enfoque de los contenidos, vemos que vuelve a prevalecer el tono informativo sobre el publicitario. Manos Unidas es la única organización que prioriza el uso de Twitter para llamar a la colaboración ciudadana a través de donativos, coincidiendo con el ya mencionado desastre de Filipinas. En esta línea el resto de ONGD se decanta por enfatizar en las historias y testimonios que otorgan un enfoque más humano a las intervenciones desarrolladas en el citado país víctima de un tifón.

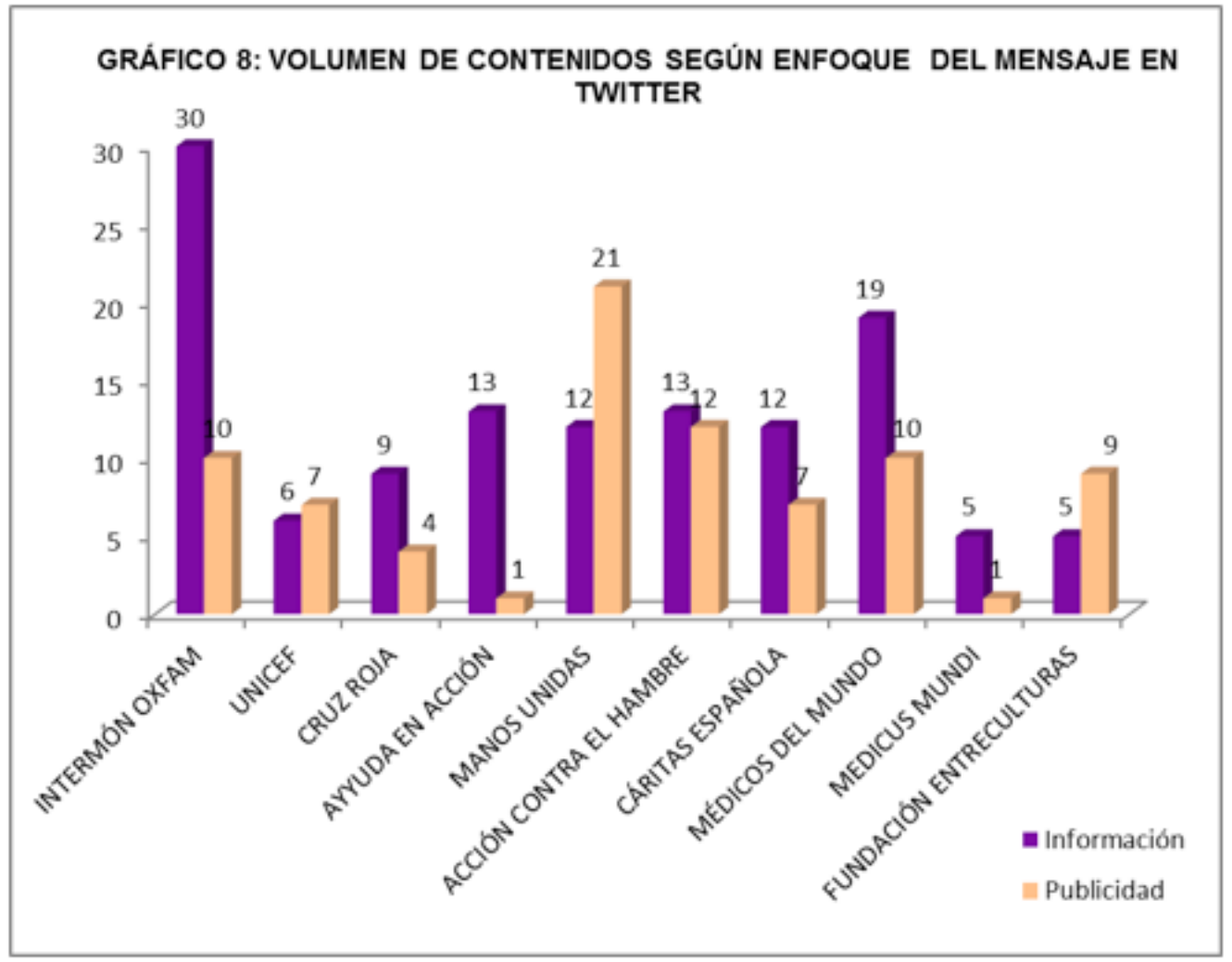

Fuente: elaboración propia

Unicef es la entidad que hace más populares los contenidos que publica en Facebook. Hasta un máximo de 
4.430 "me gusta" se han detectado durante el mes de noviembre en la publicación más notoria. Ello quiere decir que más de 4.000 usuarios han coincidido en poner de manifiesto su preferencia por la divulgación de mensajes de la entidad. Por el contrario, Medicusmundi es la organización en la que se presentan menos apoyos, puesto que se registra un intervalo de entre 1 y 3 "me gusta" durante el período de análisis señalado. Ello viene determinado también por tratarse de la organización que emite menos publicaciones en Facebook. De hecho, tal y como se puede comprobar en el Gráfico 7, solamente registra 6 entradas durante noviembre.

\begin{tabular}{|c|c|}
\hline \multicolumn{2}{|c|}{ TABLA 4: VOLUMEN DE INTERACCIONES DE USUARIOS } \\
\hline ONGD & INTERVALOS "ME GUSTA" \\
\hline Intecoón Oxfạo & $139-1.036$ \\
\hline Unicef & $341-1.337$ \\
\hline Cruz Roja Española & $14-337$ \\
\hline Ayuda en Acción & $230-1.755$ \\
\hline Manos Unidas & $287-1.619$ \\
\hline Acción contra el Hambre & $64-409$ \\
\hline Cáritas & $125-538$ \\
\hline Médicos del Mundo & $1-3$ \\
\hline Medicusmunodi & $20-67$ \\
\hline Eatreculturas & \\
\hline
\end{tabular}

Fuente: elaboración propia

El mapa de públicos que nos encontramos en Facebook está más unificado que en Twitter. Ello provoca que la mayoría de usuarios que interactúan frente a los mensajes emitidos por las ONGDs sean mayoritariamente ciudadanos de a pie. Sin embargo, es menos frecuente la intervención de públicos internos (donantes, socios, voluntarios o trabajadores). Un criterio muy similar al que nos encontramos en el microblogging. En ambos casos, se debe matizar, los públicos internos actúan como intermediarios/portavoces de las entidades, puesto que cuentan sus experiencias para hacer una llamada a los públicos externos a la colaboración directa. Volviendo a Facebook, y como se aprecia en el Gráfico 9, Manos Unidas es la organización que recibe un mayor aluvión de comentarios a sus mensajes por parte de la ciudadanía; en total 316 personas se convierten también en portavoces de la ONGD, puesto que la totalidad de usuarios interviene para apoyar la labor de las entidades. Una tendencia que se mantiene en el resto de organizaciones, y que pone de manifiesto que la mayoría de la ciudadanía que aporta sus comentarios a las divulgaciones de las entidades lo hace para avalar su actividad; ello provoca que gran parte de los usuarios se muestre sensibilizados con la causa que defiende la ONGD (15). 


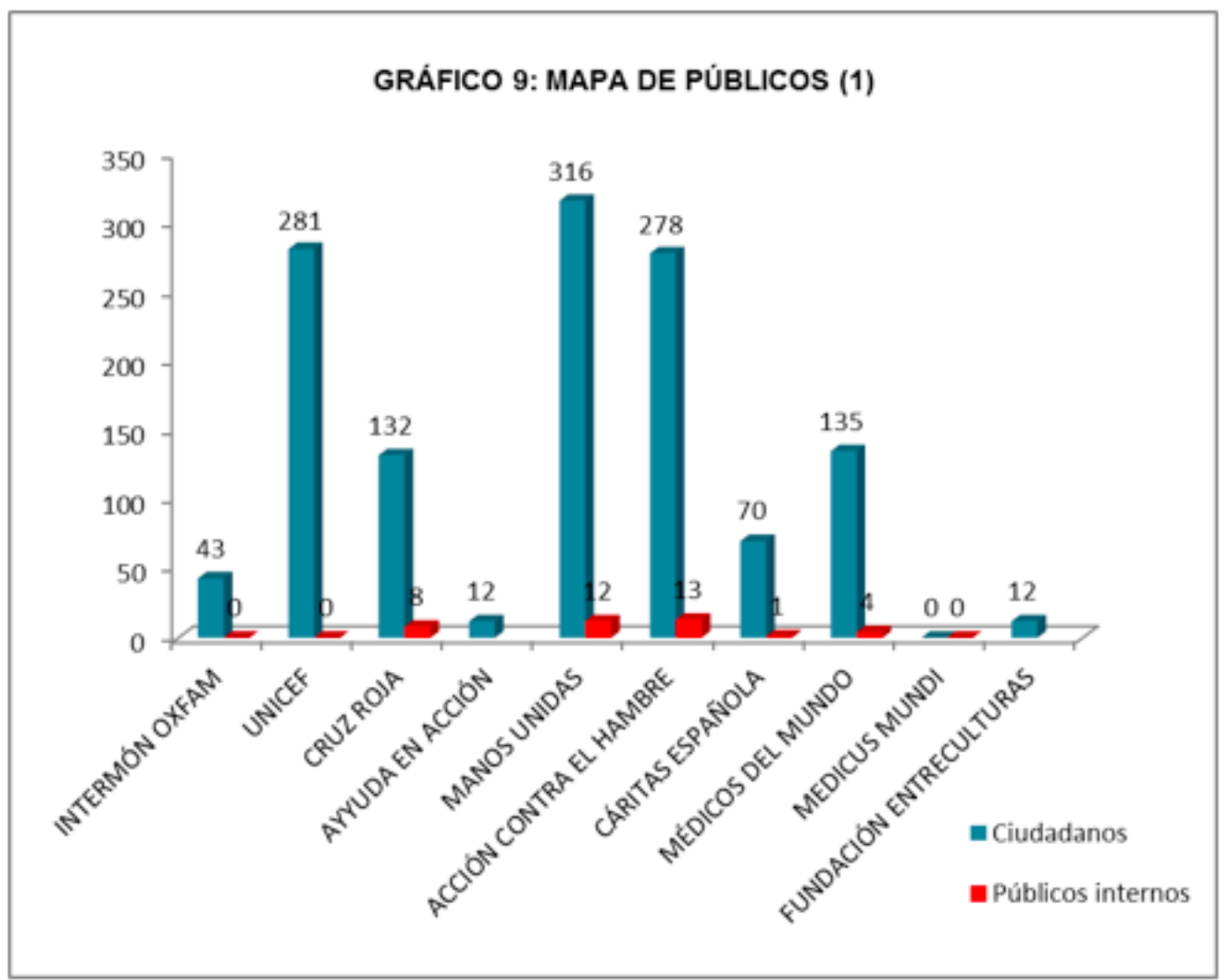

Fuente: elaboración propia

Por último, nos centramos en la inclusión del material multimedia. A diferencia de Twitter, Facebook permite mostrar el material audiovisual de una forma mucho más clara y visual. Ello hace que las ONGD se decanten por esta red social para incluir su información gráfica. En este sentido solamente cabe mencionar que la entidad que rentabiliza más las posibilidades que ofrece Facebook es Entreculturas, ya que se contabilizan un total de 256 fotografías. En este caso, nos encontramos con que la entidad opta por crear álbumes con las imágenes más relevantes, en la mayor parte de los casos relacionados con eventos de la organización o bien con la cooperación que presenta a Filipinas. En el resto de entidades se mantiene esta tendencia temática, aunque el volumen de material audiovisual es más discreto.

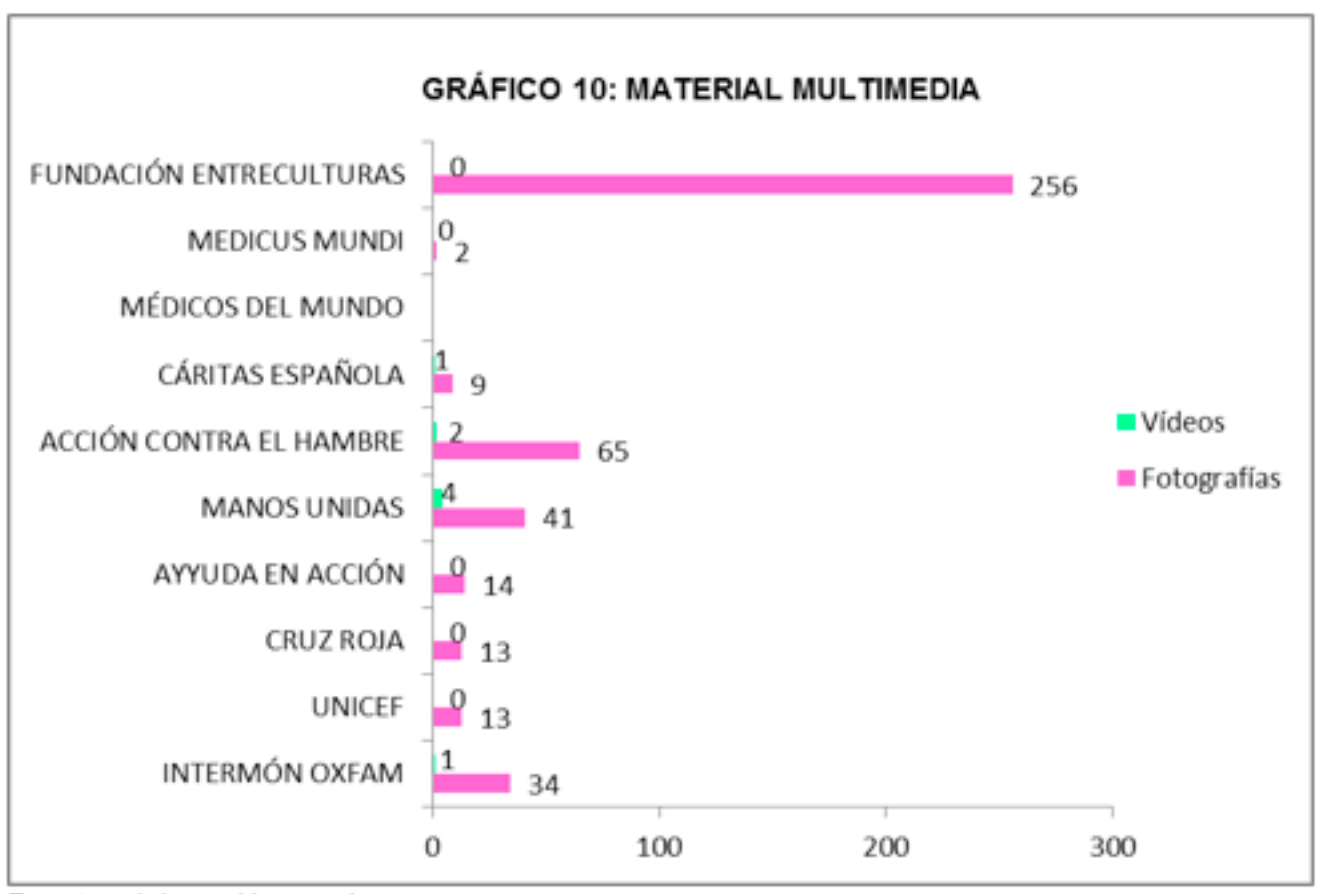

Fuente: elaboración propia

\section{CONCLUSIONES}

Pese a que, como se mencionó al inicio de la investigación, todos los estudios realizados sobre la gestión 
estratégica de la comunicación en el Tercer Sector ponen el acento en que el criterio económico es su principal factor de impulso, en el caso de la planificación a través de las redes sociales descubrimos que se cae esta premisa (16).

Hemos comprobado que el factor económico no es determinante para desplegar una estrategia de comunicación online. Un ejemplo de ello es Manos Unidas, una organización que cuenta con una ejecución de ingresos de 52.993.572, que se sitúa por debajo de otras entidades con más capital como pueden ser Intermón Oxfam o Unicef, y que sin embargo es la entidad que arroja una media más importante de noticias en Twitter (560 en el mes de noviembre).

Pero además, y sobre el uso de los medios sociales para convertir el mensaje en publicidad o en información, podemos decir que prevalecen los contenidos de carácter divulgativo. El marketing queda así en un segundo apartado, si bien es cierto que se utiliza de un modo directo cuando las ONGD lanzan llamamientos a la ciudadanía para cooperar económicamente con alguna causa. En los casos analizados esta estrategia de marketing directo se debe a la catástrofe de Filipinas.

No obstante, hay que recordar que en Twitter la organización que emite un mayor número de mensajes de carácter publicitario durante el mes de noviembre es Intermón Oxfam (50, frente a los 257 informativos). En el caso del microblogging, la entidad que ocupa esta posición es Manos Unidas, y se convierte en la única ONGD analizada que emite un mayor volumen de contenidos directos ( 21 sobre 12 de carácter informativo).

En cuanto al mapa de públicos, nos encontramos con la mayor parte de usuarios que interaccionan con las ONGD tanto en Twitter como en Facebook son ciudadanos de a pie. Casi en la totalidad de los comentarios vertidos adquieren un tono positivo. En menor medida encontramos la presencia de públicos internos, pese a que se trata de una estrategia muy recurrente para aportar credibilidad a los mensajes que publican las entidades no lucrativas. Así, y en el caso de Twitter, creemos que son muy valiosas las aportaciones de los mismos, aunque escasas ( 2 ó 3 comentarios por ONGD). También es destacable la participación de las organizaciones del Tercer Sector, pues sus comentarios contribuyen a reforzar la imagen positiva de las cuentas de Twitter de las ONGD objeto de estudio y, por supuesto, fortalecen la credibilidad de las mismas ante sus públicos potenciales y reales. La cooperación online de los medios de comunicación mantiene ese impulso hacia la confianza social en las organizaciones no lucrativas. Aunque de nuevo no es lo más habitual, en el caso de Unicef encontramos que hasta 7 medios de comunicación distintos ayudan a divulgar sus líneas de actuación, fundamentalmente las relacionadas con el tifón de Filipinas.

Dicho lo anterior, y teniendo en cuenta que hemos detectado hasta un máximo de 157.667 seguidores (Unicef), vemos que existe una gran vinculación de los públicos que siguen a las ONGD en Twitter, hasta tal punto que la media de comentarios por parte de los usuarios es mayor que en Facebook.

En Facebook mengua el número de seguidores pero ello no repercute negativamente en el grado de vinculación de la ciudadanía con la ONGD. Aunque bien es cierto que en términos generales se aprecia una menor participación, sobre todo en el caso de Medicus Mundi (no se registran comentarios de sus públicos), contemplamos positivamente el volumen de comentarios que la ciudadanía emite para la ONGD (hasta 316 en total en el caso de Manos Unidas durante el mes noviembre).

Por lo tanto, y para determinar el mapa de públicos, tal y como nos proponíamos al inicio de la investigación, podemos decir que la fortaleza de Twitter se encuentra en la variedad de públicos que apoyan su actividad y refuerzan su imagen (ciudadanía, medios de comunicación, públicos internos e incluso administración pública), mientras que en Facebook determinadas ONGD cuentan con aluviones de comentarios positivos que refuerzan su liderazgo en la mencionada red social.

Coincidiendo con el tercer y último objetivo propuesto, recalcamos que los usuarios que entran a formar parte de los contenidos de las organizaciones se muestran concienciados con la causa que define la labor de las entidades y contribuyen a reforzar su imagen social.

Sin embargo, vemos que, sobre todo en el caso de Twitter, no es habitual encontrar la figura del voluntario o del socio, una presencia muy relevante para conseguir nuevos apoyos y, sobre todo, para contribuir a desmitificar la 
vinculación latente entre organizaciones sociales y poderes públicos.

En términos generales, se ha detectado un mayor feedback en Twitter que en Facebook. Las ONGD han sabido rentabilizar la instantaneidad del medio, y dejan en un segundo plano a la red social de carácter generalista, en la que el impacto social es menor. Sin embargo, es importante recalcar que en los últimos dos años las entidades no gubernamentales que trabajan en la cooperación al desarrollo han sabido optimizar el medio social para acercarse a la ciudadanía.

Con las redes sociales, sin duda, el Tercer Sector legitima su base social y vuelve a su origen ciudadano. Quizá haya llegado la hora de cambiar el sustento que impulsa su actividad, y creemos, a tenor de los resultados, que los nuevos medios son los responsables de una tendencia creciente a ejecutar más ingresos privados que públicos (17).

\section{BIBLIOGRAFÍA}

ALMANSA, A. (2003): Teoría, estructura y funcionamiento de los gabinetes de comunicación. El caso andaluz (tesis doctoral). Málaga: Universidad de Málaga.

ASOCIACIÓN ESPAÑOLA DE LA ECONOMÍA DIGITAL (2012): Estudio Uso de Twitter en España. Madrid: Adigital

FERNÁNDEZ, M. J. (2004): Las RRPP como gestión de la comunicación en los movimientos sociales. Análisis de la estrategia de las ONG en España (tesis doctoral publicada). Málaga: Universidad de Málaga.

GARCÍA OROSA, B. (2009): Gabinetes de Comunicación online. Claves para generar información corporativa en la Red. Zamora: Comunicación Social ediciones y publicaciones

GARCÍA, B. (2006): "Aproximación teórica a la comunicación en el Tercer Sector. La necesaria reclasificación de la comunicación organizacional” en Telos: Cuadernos de comunicación e innovación, núm. 69. Madrid:

Fundación telefónica. Documento disponible en:

http://sociedadinformacion.fundacion.telefonica.com/telos/articuloperspectiva.asp@idarticulo=3\&rev=69.htm.

Fecha de consulta: 22/07/2010.

GÓMEZ GIL, Carlos (2004): Las ONG en la globalización. Estrategias, cambios y transformaciones de las ONG en la sociedad global. Barcelona: Icaria Editorial.

GÓMEZ GIL, Carlos (2005): Las ONG en España. De la apariencia a la realidad. Madrid: Los libros de la catarata.

GONZÁLEZ, H. (2006): Estrategias de comunicación en las ONG de Desarrollo. Departamentos, funciones e impacto en los medios. Madrid: CIDEAL- Fundación Asistencia Técnica para el Desarrollo (ATD).

GRANDA, G.; LUTZ, M. (1988): Las Organizaciones no Gubernamentales en la Cooperación para el Desarrollo. Madrid: CIDEAL.

GREENBERG, J.; MACAULAY, M. (2009): "NPO 2.0?. Explolring the Web Presence of Environmental Nonprofit Organizations in Canada" en Global Media Journal. Canadá: University of Ottawa.

HERRANZ DE LA CASA, J. M. (2006): La comunicación y la transparencia en las Organizaciones No Lucrativas. Madrid: Universidad Complutense de Madrid.

INGENHOFF, D.; KOELLING, A (2009): "The potencial of Web sites as a relationship building tool for charitable fundraising NPOs" en Public Relations Review, num. 35 (pp. 66-73). Amsterdam: Elsevier.

KANG, S.; NORTON, H. (2004): "Nonprofif organizations's use of the World Wide Web: are they sufficiently fulfilling organizational goals?" en Public Relations Review, num. 30 (pp. 279-284). Amsterdam, Elsevier.

KENT, Michael L.; TAYLOR, Maureen; WHITE, William J. White (2002): "The relationship between Web site 
design and organizational responsive to stakeholders" en Public Relations Review (pp. 63-77), núm. 29. Amsterdam: Elsevier.

MARCUELLO, C. (1996): "Las Organizaciones No- Gubernamentales de Desarrollo y la construcción positiva de su identidad" en Acciones e Investigaciones Sociales, n. 5 (pp. 103-120). Zaragoza: Universidad de Zaragoza.

MARCUELLO, C. (Coord.). (2007): Capital social y Organizaciones No Lucrativas en España. El caso de las ONGD. Bilbao: Fundación BBVA.

NAUDÉ, A., M. E.; FRONEMAN, J. D.; ATWOOD, R. (2003): "The use of the internet by then South African nongovernmental organizations- a public relations perspective" en Public Relations Review vol. 30 (pp. 87-94).. Amsterdam. Elsevier.

RAMíREZ, T. (1995): Gabinetes de comunicación. Funciones, disfunciones e incidencia. Barcelona: Bosch Casa Editorial.

SAMPEDRO, V.; JEREZ, A.; LÓPEZ REY, J. (2002): "Imagen pública y estrategias de comunicación”, en BLANCO REVILLA, M. (Ed.) (2002): Las ONGs y la política (pp. 251-281). Madrid: Ediciones Istmo.

SERRANO, M. (2001): "Las ONG entre la empresa y el Estado: ¿Cambio o reproducción del sistema” en NIETO PEREIREA, Luis (Coord.) (2001): Cooperación para el desarrollo y ONG (pp. 141-169). Una visión crítica.Madrid: Los libros de la catarata.

SORIA, M.M. (2011): La comunicación de las ONG españolas: influencia de Internet en el modelo estratégico de relaciones con los públicos. Málaga: Servicio de Publicaciones Universidad de Málaga.

TAYLOR, M.; KENT, M. (2010): "Anticipatory socialization in the use of social media in Public Relations: A content analysis of PRSA's Public Relations Tactics” en Public Relations Review, num. 36 (pp. 207-214). Amsterdam: Elsevier.

(01) Marcuello Servós (2007: 87) utiliza como fuente de los datos dados a Mota (1999), CIS (1996) y Estudio CIS 2.218 (1996).

(02) Marcuello Servós (2007: 91) obtiene los citados datos del CIS (Número 2.450; año 2002).

(03) Recordamos que entre 1980 y 1990 surgen 51 organizaciones, lo que significa el 76\% de las ONGDs federadas a la Coordinadora Española de ONG para el Desarrollo (Baiges et al., 1996: 98). Ello es un claro indicio de que las ONGs españolas empezaban a tener una presencia importante en nuestro país, algo que hace más visible en el transcurso de los años noventa, como consecuencia de acontecimientos determinantes tales como las manifestaciones ciudadanas en 1997 para pedir al Gobierno que destine el 0,7\% del PIB para ayuda al desarrollo.

(04) Tomamos como referencia esta premisa para seleccionar la muestra, tal y como se especifica en el apartado correspondiente.

(05) Según la Asociación Española de Economía Digital (adigital) Twitter cerró el año 2012 con una ratio de 500 millones de usuarios activos en España.

(06) La propia compañía revela en septiembre de 2013 que el número de usuarios españoles que tienen cuenta en la red social asciende a 18 millones.

(07) La CONGD emite el mencionado informe anualmente. En el mismo se encuentran desglosadas las memorias de actividades, presupuestos, ingresos y gastos de las ONGD vinculadas a la Coordinadora. Se toma como referencia el último documento publicado en el momento de la investigación.

(08) Referencia: CONGDE (2011: 52). 
(09) Aunque partimos de la base de que la gestión estratégica de la comunicación en redes sociales se articula a coste cero, sí que hemos de tener en cuenta que las ONGD necesitan personal para llevar a cabo esta función. En organizaciones de gran calado, como son las analizadas, se trata de personas asalariadas.

(10) Para una investigación a mayor escala hubiera sido conveniente analizar los tres meses. Sin embargo, en este caso, la ingente cantidad de datos cuantitativos analizados, como se pone de manifiesto, son coherentes con los objetivos y alcances propuestos en el presente estudio.

(11) Las ONGD que no presentan fecha no han respondido a la solicitud realizada para la presente investigación.

(12) Entendemos por grupos la categorización de públicos realizada para el presente estudio y que se pone de manifiesto en los gráficos y en la tabla que refleja la citada segmentación.

(13) Ver gráfico 3

(14) Datos proporcionados por la consultora Alexa: Usuarios de redes sociales en España 2012.

(15) Solamente en el caso de Cáritas se ha detectado una crítica procedente de un ciudadano en la que se alude a la falta de credibilidad que le inspira la actividad de la ONGD al mismo. Cabe mencionar que la entidad no emite ninguna respuesta ante la citada opinión. Ello provoca que el resto de usuarios no le otorgue importancia y, por lo tanto, no se ha generado un debate en torno a ello.

(16) Recordemos que los estudios desarrollados por Sampedro et al (2002:283) Fernández Torres (2004: 896) revelan que cuanto mayor sea el presupuesto de una ONGD, más invertirá en comunicación y en imagen de marca.

(17) En la Tabla 1 se puede observar que 6 de las 10 ONGD objeto de estudio cuentan con mayor volumen de ingresos públicos que privados.

\section{Breve semblanza de la autora:}

María del Mar Soria Ibáñez es profesora contratada con grado de Doctora en el Centro de Estudios Superiores Felipe II. Universidad Complutense de Madrid

Ámbitos. Revista Internacional de Comunicación, n.27, año 2014, cuarto trimestre (invierno).

Recibido: 13/08/2014

Aprobado: 24/11/2014 